\title{
A Three-Dimensional Enormous Surface Area Aluminum Microneedle Array with Nanoporous Structure
}

\author{
Po Chun Chen, ${ }^{1}$ Sheng Jen Hsieh, ${ }^{2}$ Chien Chon Chen, ${ }^{3}$ and Jun Zou ${ }^{1}$ \\ ${ }^{1}$ Department of Electrical Engineering, Texas A\&M University, College Station, TX 77843-3128, USA \\ ${ }^{2}$ Department of Engineering Technology, Texas A\&M University, College Station, TX 77843-3128, USA \\ ${ }^{3}$ Department of Energy Engineering, National United University, Miaoli 36003, Taiwan
}

Correspondence should be addressed to Chien Chon Chen; chentexas@gmail.com and Jun Zou; junzou@ece.tamu.edu

Received 24 December 2012; Accepted 3 January 2013

Academic Editor: Amir Kajbafvala

Copyright (C) 2013 Po Chun Chen et al. This is an open access article distributed under the Creative Commons Attribution License, which permits unrestricted use, distribution, and reproduction in any medium, provided the original work is properly cited.

\begin{abstract}
We proposed fabricating an aluminum microneedle array with a nanochannel structure on the surface by combining micromachining, electrolyte polishing, and anodization methods. The microneedle array provides a three-dimensional (3D) structure that possesses several hundred times more surface area than a traditional nanochannel template. Therefore, the microneedle array can potentially be used in many technology applications. This 3D microneedle array device can not only be used for painless injection or extraction, but also for storage, highly sensitive detection, drug delivery, and microelectrodes. From the calculation we made, the microneedle array not only increases surface area, but also enlarges the capacity of the device. Therefore, the microneedle array can further be used on many detecting, storing, or drug delivering applications.
\end{abstract}

\section{Introduction}

Puncturing the human skin with a needle or a patch is the most common invasive medical procedure to deliver or extract fluids from the human body. During the past few years, developing painless needles or patches to replace the traditional hypodermic needles has been investigated [1-3]. The mosquito's proboscis should be a good model for painless insertion. Up to $1.5 \mathrm{~mm}$ penetration depth can be painless [4]. The type of drug release needle offers the advantages of convenience inset in the skin, high surface area for drug absorption, easy to control the period of drug release by temperature, and high resolution and quick of detection when the needle with indicator absorption. Because of a fast switching time and high quantity of the drugs, this needle could be used for emergency therapy, which requires acute and on-demand drug delivery [5-7].

Silicon has been processed to make microneedles and microneedle arrays by conducting micromachining or photolithography technology. This microneedle array, with a needle length of $0.15 \mathrm{~mm}$, diameter of $80 \mathrm{um}$ at the base and a tip radius of $1 \mathrm{um}$, can be a painless device for injection or extraction [8]. However, crystal silicon anisotropy limits the sharpness of the microneedle, and micromachining of silicon is costly and complex. Thus, we propose aluminum as an alternative material for fabricating microneedles or arrays of microneedles. The micromachining technique is able to construct a high-density micropillar array on aluminum. In addition, we fabricated a very sharp AAO needle with $1 \mathrm{um}$ diameter by electrolyte polishing in previous work [9]. A nanochannel structure of anodic aluminum oxide that has controllable pore sizes from $10 \mathrm{~nm}$ to $500 \mathrm{~nm}$, pore density from $10^{7}$ to $10^{10}$ pore $\cdot \mathrm{cm}^{2}$, and tube length from $0.1 \mu \mathrm{m}$ to $30 \mu \mathrm{m}[10-13]$.

Aluminum anodization is probably the most controllable self-assembly processes at lower cost. The anodized aluminum oxide (AAO) possesses unique features, such as high aspect ratio, uniform pore size, high surface area, and high structural ordering degrees. The AAO template has been used for one-dimensional organic nanostructures, nanowires, and solar cell applications [14-16]. Unlike microstructures made of glass, metal, silicon which may fracture, or polymeric which may bend the toughness aluminum/anodic aluminum oxide (Al/AAO) microneedle array do not break or bend 
under extreme force. Therefore, a more dense and submicron needle array can be achieved. A large surface area and dense needle array of nanotube film which can also carry more drug capacity. In this research, we have developed a novel electrochemical processes investigation and fabrication a tiny needle array and nanotube film under ambient conditions, thereby enabling low-cost and mass production of the needle array.

\section{Experimental Procedures}

The aluminum micropillar array was fabricated by micromachining process using diamond blade on an aluminum piece $(99.99 \%$ purity) with $10 \mathrm{~mm}$ thickness. There were 20 cuts in each direction ( $x$ and $y$ ), and the distance between two pillars were $500 \mathrm{um}$ and the depth was $5 \mathrm{~mm}$. The sharpening process was conducted by electrochemical polishing. The aluminum pillar array was electropolished at $15 \mathrm{~V}$, in a bath of $15 \mathrm{vol} . \%$ perchloric acid $\left(\mathrm{HClO}_{4}\right)$, 70 vol.\% ethanol $\left(\mathrm{C}_{2} \mathrm{H}_{5} \mathrm{OH}\right)$, and 15 vol.\% butyl cellosolve $\left(\mathrm{CH}_{3}\left(\mathrm{CH}_{2}\right)_{3} \mathrm{OCH}_{2} \mathrm{CH}_{2} \mathrm{OH}\right)$ solution at $20^{\circ} \mathrm{C}$ for $5 \mathrm{~min}$. Then the alumninum needle array was anodized at $80 \mathrm{~V}$ using a platinum plate as the counter electrode in 1 vol.\% phosphoric acid $\left(\mathrm{H}_{3} \mathrm{PO}_{4}\right)$ electrolyte at $2^{\circ} \mathrm{C}$ for 30 minutes, or at $40 \mathrm{~V}$ in $3 \mathrm{wt} . \%$ oxalic acid $\left(\mathrm{C}_{2} \mathrm{H}_{2} \mathrm{O}_{4}\right)$ electrolyte at $20^{\circ} \mathrm{C}$ for 30 minutes. After anodization, a 3D microneedle array structure with large AAO surface area can be formed. Figure 3 shows the scheme of the aluminum needle array. The topography of the AAO-coated needle array was observed using an FEI QUANTA 600 field emission scanning electron microscope.

\section{Results and Discussion}

Anodic aluminum oxide, also known as $\mathrm{Al}_{2} \mathrm{O}_{3}$ or $\mathrm{AAO}$, is a ceramic with a high melting point and great hardness. $\mathrm{AAO}$ is also an environmentally friendly and biologically compatible material used in medical and biotechnology applications. Figure 1 shows a schematic diagram of the AAO template on an aluminum substrate; (a) AAO structure with aluminum substrate and barrier layer, (b) AAO side view with straight channels, and (c) ordering nanopores arrange on the AAO film. The pore diameter and pore density can be controlled by applied voltage, and the film thickness can be controlled by anodization time. Figure $1(\mathrm{~b})$, a side view of the AAO structure, shows an open pore on the top, a closed end or barrier layer on the bottom, and an aluminum substrate under the AAO film.

The AAO surface area can be calculated based on structural parameters such as thickness $(D)$, pore size $(2 r)$, pore density $(\rho)$, and sample size (unit area). The AAO surface area $(2 \pi r \rho D)$ increases with film thickness. If AAO pores are ordering closed packaging arrange the $\mathrm{AAO}$ with pore diameters of $15 \mathrm{~nm}, 60 \mathrm{~nm}$, and $500 \mathrm{~nm}$, the pore density can be computed as $2.6 \times 10^{11}, 1.5 \times 10^{10}$, and $1.5 \times 10^{8}$ pore $/ \mathrm{cm}^{2}$. Figure 2 showed the AAO surface area and SEM images, (a) evaluated curves of AAO surface area based on a $1 \mathrm{~cm}^{2}$ substrate, (b) AAO with $15 \mathrm{~nm}$ pore size, (c) AAO with $60 \mathrm{~nm}$ pore size, and (d) AAO with $500 \mathrm{~nm}$ pore size. For example,

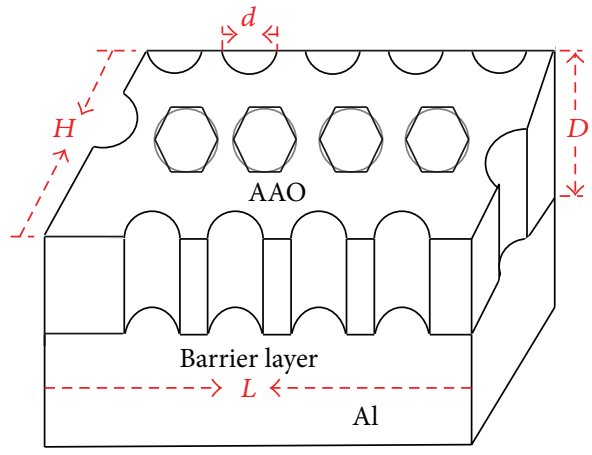

(a)

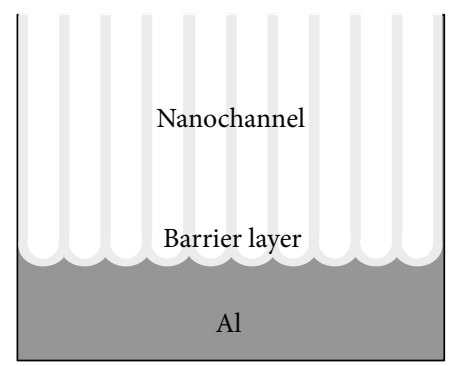

(b)

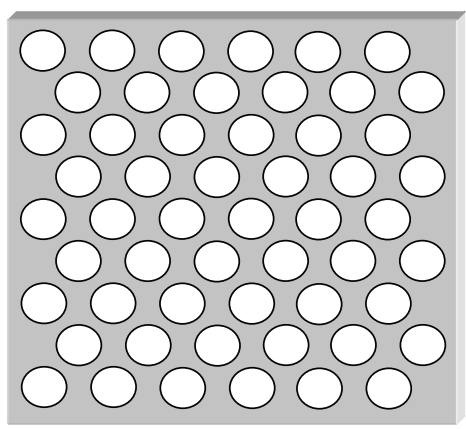

(c)

FIgURE 1: The schematic diagram of (a) AAO structure with aluminum substrate and barrier layer, (b) AAO side view with straight channels, and (c) ordering nanopores arrangement on the AAO film.

when AAO thickness is $20 \mu \mathrm{m}$, the pore surface areas are $2150 \mathrm{~cm}^{2}, 537 \mathrm{~cm}^{2}$, and $64 \mathrm{~cm}^{2}$ for diameters of $15 \mathrm{~nm}, 60 \mathrm{~nm}$, and $500 \mathrm{~nm}$, respectively.

When the aluminum column was electropolished, the column end surface has greater electrical field than the side surface of column. Therefore, the column end can be polished to a tip. Figure 3 showed the schematic diagram of aluminum needle formation. Figure 3(a) showed aluminum column formation by mechanical cutting. The number of columns and dimension were controlled by the diamond blade. For example, in this research, there were 400 aluminum columns formed by 20 cuts in each direction ( $x$ and $y$ ) and the distance between two pillars was $500 \mathrm{um}$ and the depth was $5 \mathrm{~mm}$. Based on electrical field characteristic that the column tip has a larger current density compared to the column side 


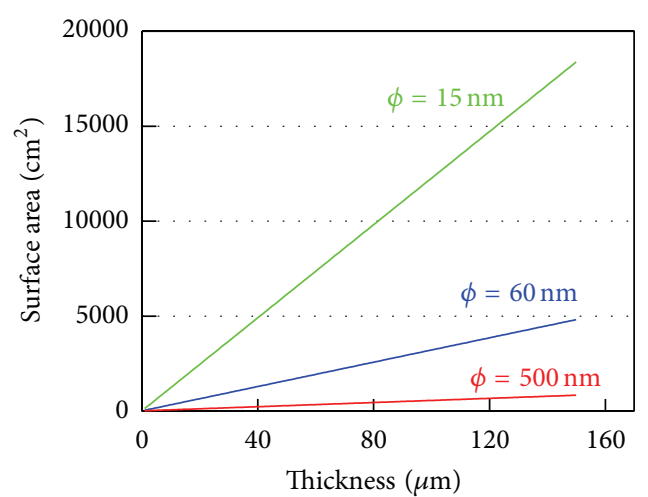

(a)

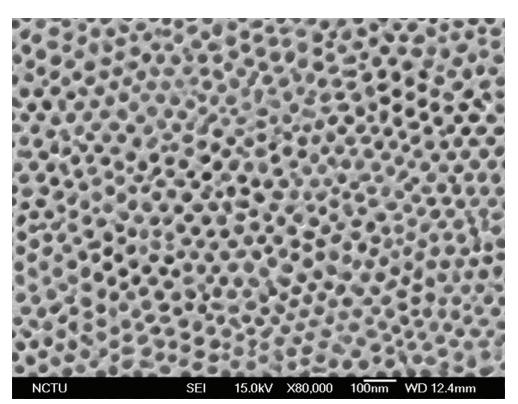

(b)

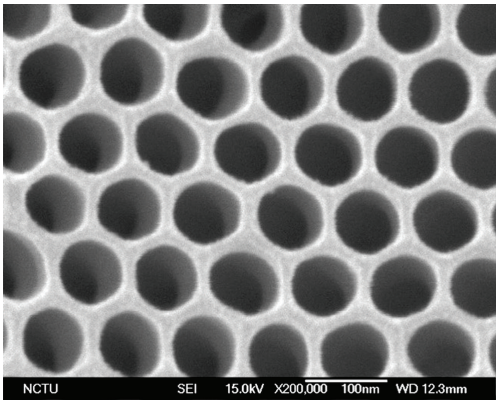

(c)

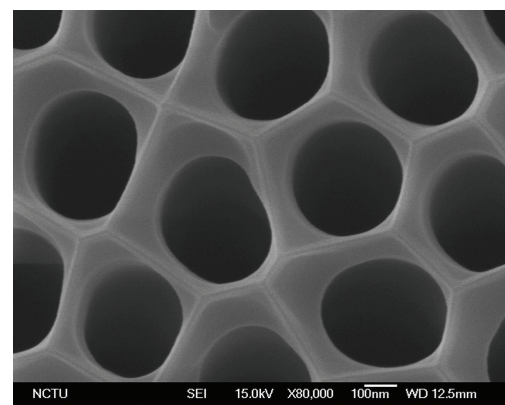

(d)

FIgURE 2: The AAO surface area and SEM images; (a) evaluated curves of AAO surface area based on a $1 \mathrm{~cm}^{2}$ substrate, (b) AAO with $15 \mathrm{~nm}$ pore size, (c) AAO with $60 \mathrm{~nm}$ pore size, and (d) AAO with $500 \mathrm{~nm}$ pore size.

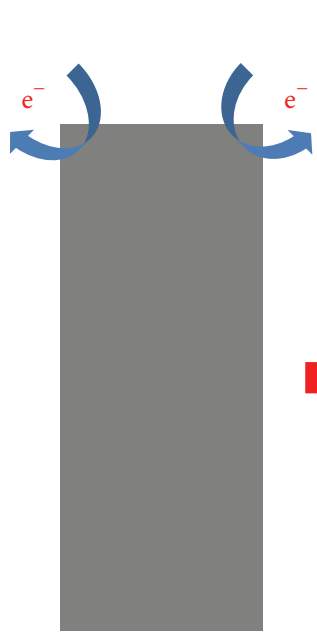

(a)

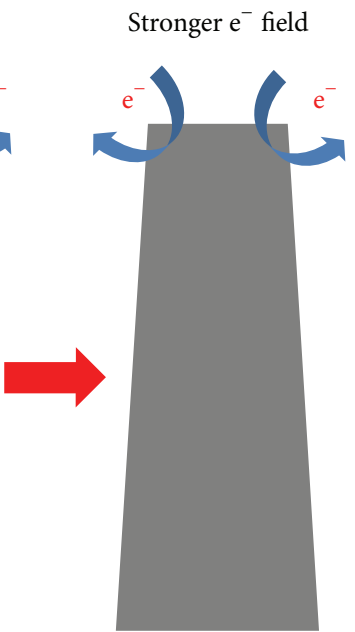

(b)

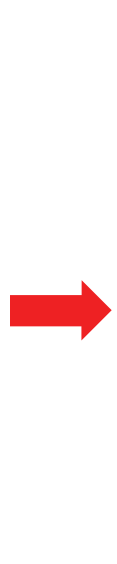

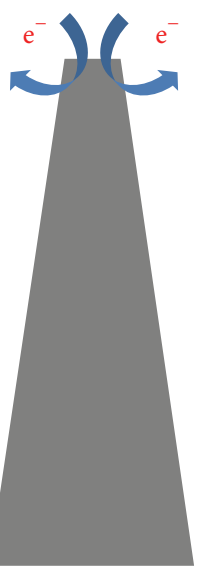

(c)

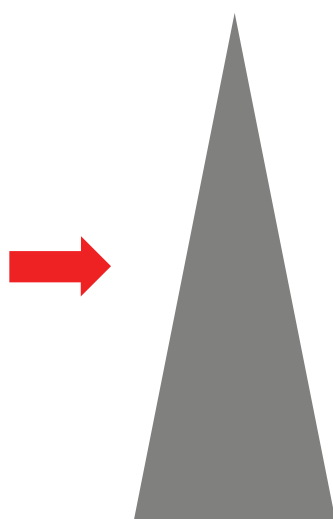

(d)

FIGURE 3: The schematic diagram of aluminum needle formation; (a) aluminum column formation by mechanical cutting, (b), (c) trapezoidshaped formation by a short time of electropolishing, (d) needle-shaped formation by a long time of electropolishing.

the tip size decreased with electropolishing time increased. Figures 3(b) and 3(c) showed a trapezoid-shaped formation by a short time of electropolishing, and Figure 3(d) showed a needle-shaped formation by a long time of electropolishing. The schematic diagrams of 3D aluminum array of (a) aluminum array columns formation by mechanical cutting, (b) aluminum array needles formation by electroolishing were showed in Figure 4. And, Figure 5 showed SEM images of (a) aluminum array columns formation by mechanical cutting, (b) aluminum array needles formation by electroolishing on a $10 \mathrm{~mm}$ thickness aluminum sheet. Figure 6 showed SEM images of (a) aluminum needle with $3.2 \mu \mathrm{m}$ tip diameter after 


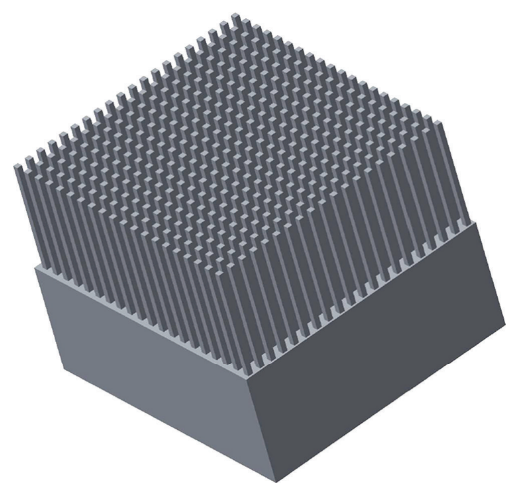

(a)

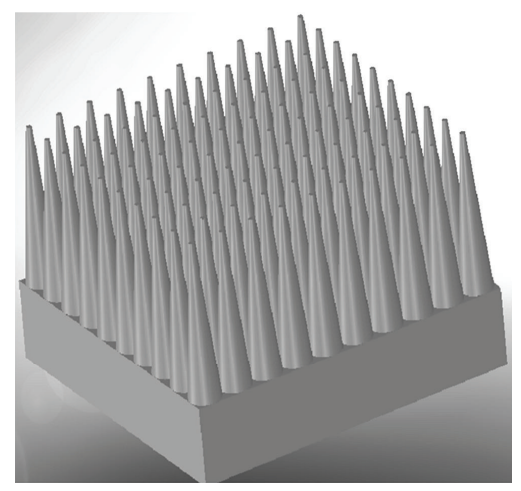

(b)

FIGURE 4: The schematic diagrams of aluminum array, (a) aluminum array columns formation by mechanical cutting, (b) aluminum array needles formation by electroolishing.

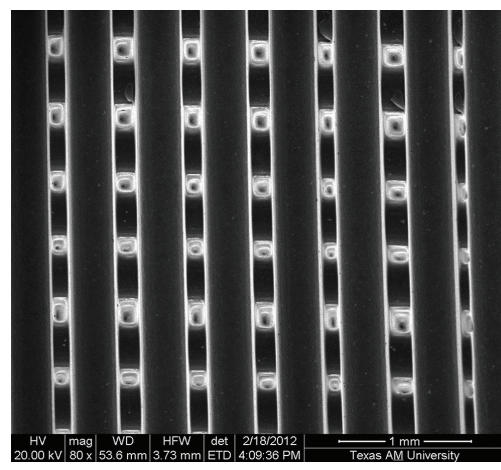

(a)

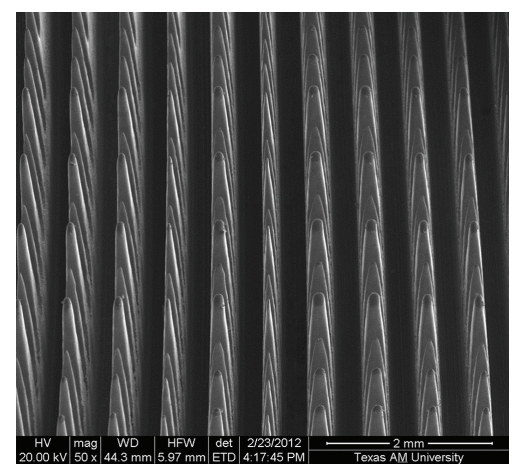

(b)

FIGURE 5: The SEM images of aluminum array, (a) aluminum array columns formation by mechanical cutting, (b) aluminum array needles formation by electroolishing.

$60 \mathrm{sec}$ electropolishing and (b) with $0.8 \mu \mathrm{m}$ tip diameter after $90 \mathrm{sec}$ electropolishing.

There were some wider tips because aluminum is soft and easy to break. Figure 7(a) showed the SEM image of the microneedle covered by an AAO film. The surface area of the microneedle array became much larger after anodization. Furthermore, anodizing the aluminum needles not only increases the surface area, but also enhances the mechanical strength. The ceramic property of the AAO tips also makes the microneedle array harder and stronger for contact or attachment with test samples. Figure 7(b) showed the SEM image of the nanoporous structure on the microneedle array. The pore diameter is about $60 \mathrm{~nm}$, and the pore density is $10^{10} / \mathrm{cm}^{2}$.

The surface area of a single microneedle is $\pi R L$ ( $L$ is the length of the microneedle, and $R$ is the pillar radius). There were 400 microneedles surface area more than a $2 \mathrm{D}$ AAO structure. For the microneedle with $5 \mathrm{~mm}$ length and $0.3 \mathrm{~mm}$ bottom diameter, the surface area of the microneedle array can be calculated as $10 \mathrm{~cm}^{2}$ in a $1 \mathrm{~cm} \times 1 \mathrm{~cm}$ sample. Comparing this AAO microneedle array with 2D AAO plate, the surface area increased 10 times. Therefore, the aluminum microneedle array has 10 times more surface area for forming AAO than an aluminum sheet.
The capacity of the painless microneedle array can be calculated from the surface area of the painless microneedle tip. According to Khumpuang et al. report [4], $1.5 \mathrm{~mm}$ depth and 100 um diameter can be painless. Thus, the aluminum pillars can be sharpened by electropolishing to obtain $5 \mathrm{~mm}$ length and 300 um bottom diameter microneedles as mentioned above. The upper $1.5 \mathrm{~mm}$ part of microneedle has 75 um diameter, so the total surface area for 400 microneedles is $1.41 \mathrm{~cm}^{2}$. Then, the aluminum microneedle tip can be anodized to form AAO nanoutubes with $5 \mathrm{um}$ length, $60 \mathrm{~nm}$ diameter, and $10^{10} / \mathrm{cm}^{2}$ pores density. Hence, the capacity $(C)$ of the microneedle array can be calculated as $2 \times 10^{-4} \mathrm{~cm}^{3}$ in a $1 \mathrm{~cm} \times 1 \mathrm{~cm}$ sample by $C=A \times \rho \times \pi \times r^{2} \times D$, where $A$ is the total surface area for the 400 microneedle tips, $\rho$ is the pore density, $r$ is the pore size, and $D$ is the thickness of AAO nanochannel.

\section{Conclusions}

In this paper, we present a convenient and cheap method to fabricate a large surface area 3D microneedle array by micromachining, electrolyte polishing, and anodizing processes. The microneedles are covered by an AAO film, which 


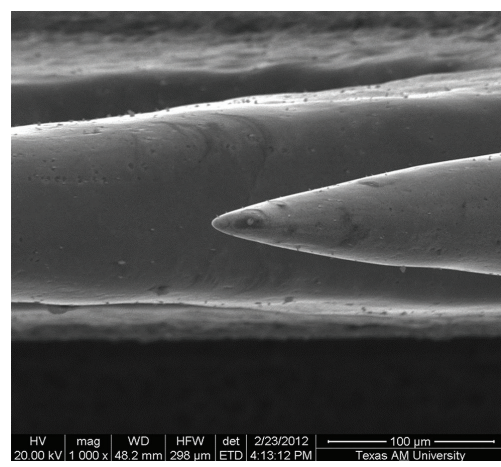

(a)

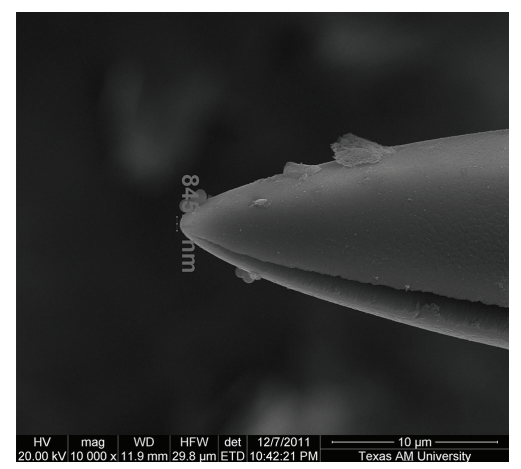

(b)

FIGURE 6: The SEM images of aluminum needle tips; aluminum needle (a) with $3.2 \mu \mathrm{m}$ tip diameter after 60 sec electropolishing and (b) with $0.8 \mu \mathrm{m}$ tip diameter after 90 sec electropolishing.

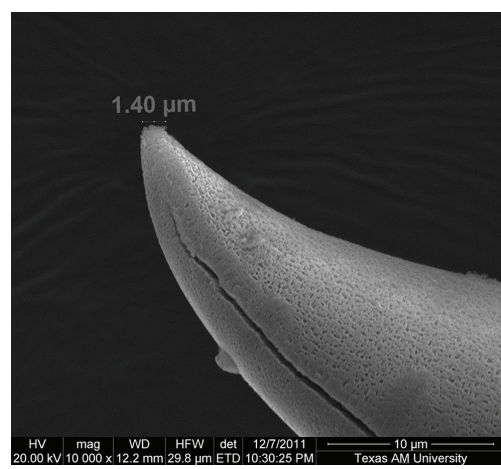

(a)

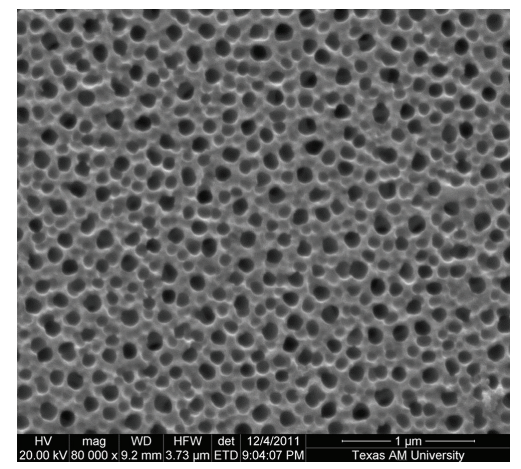

(b)

FIGURE 7: The SEM images of (a) nanopores formation on the aluminum needle by anodization and (b) pore sizes are less than $100 \mathrm{~nm}$.

has a large surface area, so they can enlarge the surface area and capacity and enhance the mechanical properties as well. The aluminum microneedle array, which is able to absorb with detecting indicators, can be used for chemical or biological detection. It can also be applied to drug delivery or storage applications because it can approach painless injection/extraction and high capacity. Furthermore, such needles can also be used with thermal and hydrophilic-hydrophobic sensitive film, for example, poly ( $\mathrm{N}$-isopropylacrylamide, PNIPAM), to develop an accurate device for drug detection and release. Our results clearly provide a concept that the microneedle covered with nanopore films such as $\mathrm{TiO}_{2}, \mathrm{WO}_{3}$, $\mathrm{Ta}_{2} \mathrm{O}_{5}$, or $\mathrm{MoO}_{3}$ can also be formed by micromachining, electropolishing, and anodization processes.

\section{Acknowledgments}

The authors would like to thank the Texas A\&M University and National United University for financially supporting this work. Part of this study was supported by a Grant from the National Science Council, Taiwan (101-2627-M-239-001-).

\section{References}

[1] A. Oki, M. Takai, H. Ogawa et al., "Healthcare chip for checking health condition from analysis of trace blood collected by painless needle," Japanese Journal of Applied Physics, vol. 42, no. 6, pp. 3722-3727, 2003.

[2] H. Ogawa, M. Nagai, J. Kikuchi, and Y. Horiike, "Blood painless collection system equipping detection functions for search of vein," in Proceedings of the 7th Intenational Confrence Miniaturized Chemical and Biochemical Analysis Systems, pp. 741-743, Squaw Valley, Calif, USA, 2003.

[3] K. Oka, S. Aoyagi, Y. Arai, Y. Isono, G. Hashiguchi, and H. Fujita, "Fabrication of a micro needle for a trace blood test," Sensors and Actuators A, vol. 97-98, pp. 478-485, 2002.

[4] S. Khumpuang, M. Horade, K. Fujioka, and S. Sugiyama, "Geometrical strengthening and tip-sharpening of a microneedle array fabricated by X-ray lithography," Microsystem Technologies, vol. 13, no. 3-4, pp. 209-214, 2007.

[5] C. Hohmann, I. Ullrich, R. Lauche, K. E. Choi, R. Lüdtke, and R. Rolke, "The benefit of a mechanical needle stimulation pad in patients with chronic neck and lower back pain: two randomized controlled pilot studies," Evidence-Based Complementary and Alternative Medicine, vol. 2012, Article ID 753583, 11 pages, 2012.

[6] H. Ito, H. Inoue, S. Ryozawa, H. Ikeda, N. Odaka, and N. Eleftheriadis, "Fine-needle aspiration biopsy and endoscopic ultrasound for pretreatment pathological diagnosis of gastric gastrointestinal stromal tumors," Gastroenterology Research and Practice, vol. 2012, Article ID 139083, 6 pages, 2012.

[7] L. X. Yang, J. J. Yin, L. L. Wang, G. Xiu Xing, P. Yin, and Q. W. Liu, "Hydrothermal synthesis of hierarchical hydroxyapatite: 
preparation, growth mechanism and drug release property," Ceramics International, vol. 38, pp. 495-502, 2012.

[8] S. Henry, D. V. McAllister, M. G. Allen, and M. R. Prausnitz, "Micromachined needles for the transdermal delivery of drugs," in Proceedings of the IEEE 11th Annual International Workshop on Micro Electro Mechanical Systems (MEMS '98), pp. 494-498, Heidelberg, Germany, January 1998.

[9] P. C. Chen, S. J. Hsieh, C. C. Chen, and J. Zou, "Fabrication and characterization of chemically sensitive needle tips with aluminum oxide nanopores for $\mathrm{pH}$ indication," Ceramics International, 2012.

[10] C. C. Chen, D. Fang, and Z. Luo, "Fabrication and characterization of highly-ordered valve-metal oxide nanotubes and their derivative nanostructures," Review in Nanoscience and Nanotechnology, vol. 1, pp. 229-256, 2012.

[11] G. C. Wood, P. Skeldon, G. E. Thompson, and K. Shimizu, "A model for the incorporation of electrolyte species into anodic alumina," Journal of the Electrochemical Society, vol. 143, no. 1, pp. 74-83, 1996.

[12] G. C. Wood and J. P. O'Sullivan, “The anodizing of aluminium in sulphate solutions," Electrochimica Acta, vol. 15, no. 12, pp. 1865-1876, 1970.

[13] C. C. Chen, Y. Bisrat, Z. P. Luo, R. E. Schaak, C. G. Chao, and D. C. Lagoudas, "Fabrication of single-crystal tin nanowires by hydraulic pressure injection," Nanotechnology, vol. 17, no. 2, pp. 367-374, 2006.

[14] R. O. Al-Kaysi, T. H. Ghaddar, and G. Guirado, "Fabrication of one-dimensional organic nanostructures using anodic aluminum oxide templates," Journal of Nanomaterials, vol. 2009, Article ID 436375, 14 pages, 2009.

[15] F. E. Atalay, D. Avsar, H. Kaya, V. Yagmur, S. Atalay, and T. Seckin, "Nanowires of lead-free solder alloy SnCuAg," Journal of Nanomaterials, vol. 2011, Article ID 919853, 6 pages, 2011.

[16] G. Y. Chen, M. W. Lee, and G. J. Wang, "Fabrication of dyesensitized solar cells with a 3D nanostructured electrode," International Journal of Photoenergy, vol. 2010, Article ID 585621, 7 pages, 2010. 

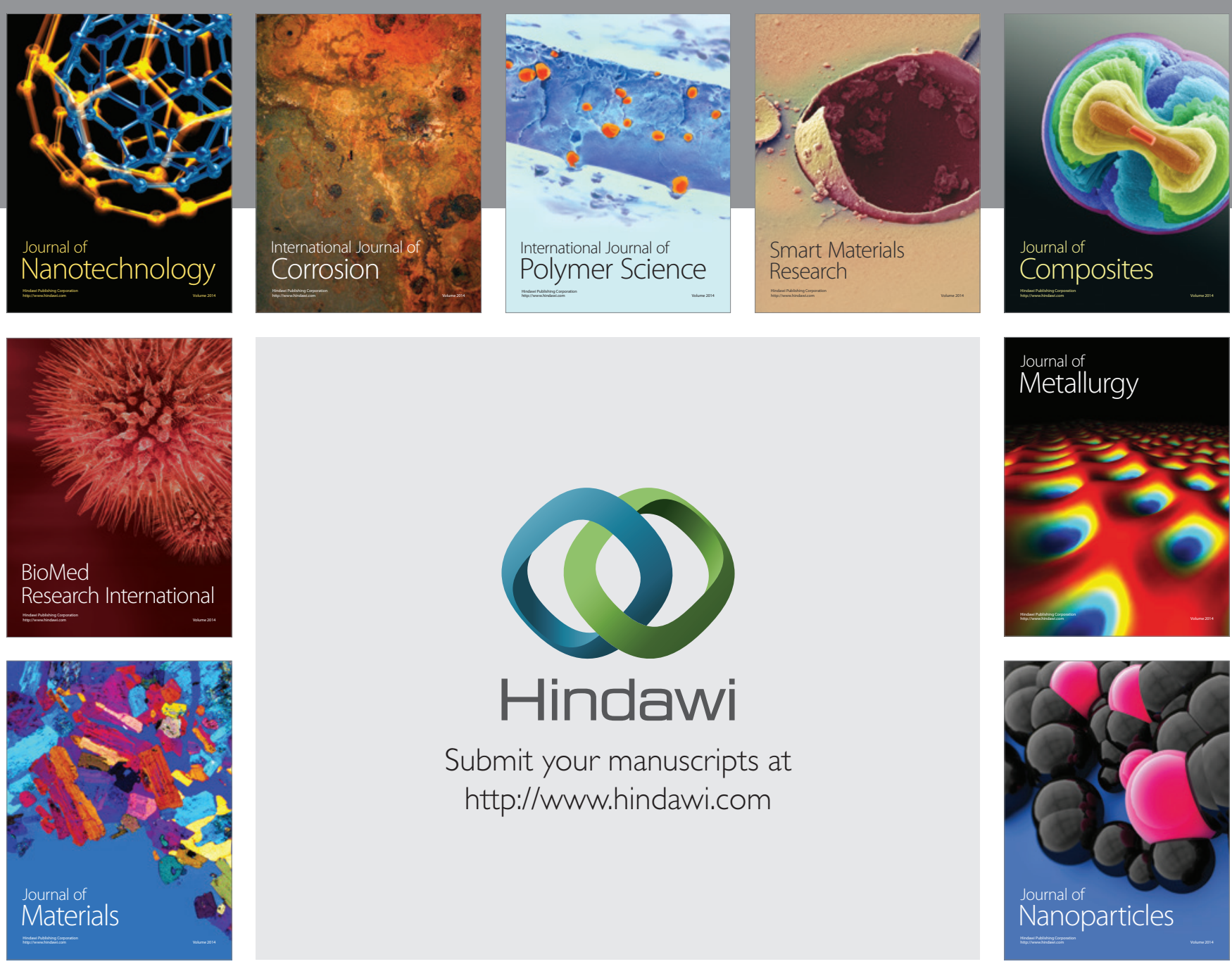

Submit your manuscripts at http://www.hindawi.com
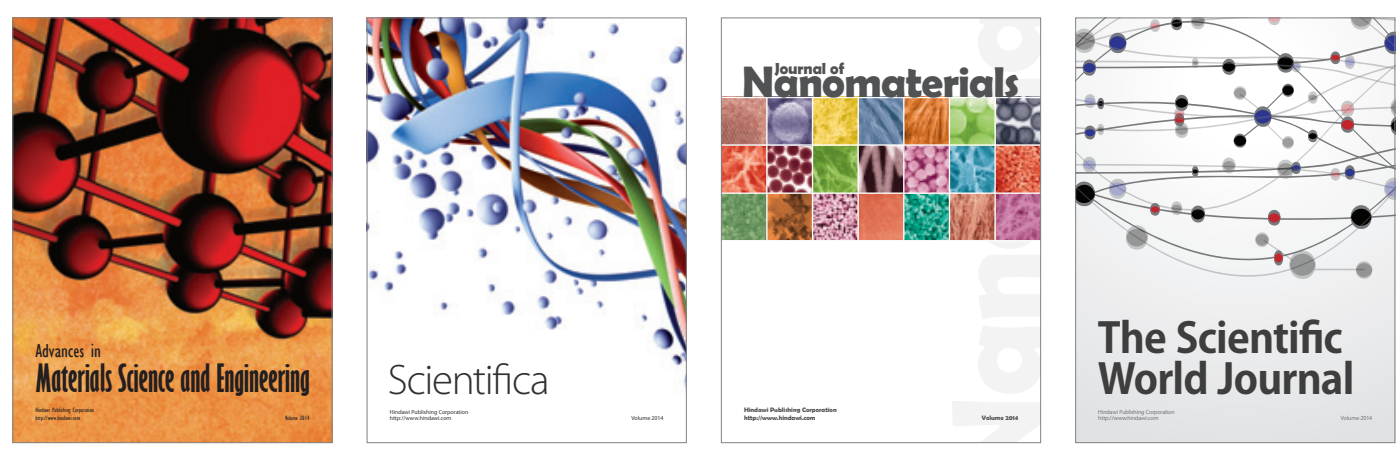

\section{The Scientific World Journal}
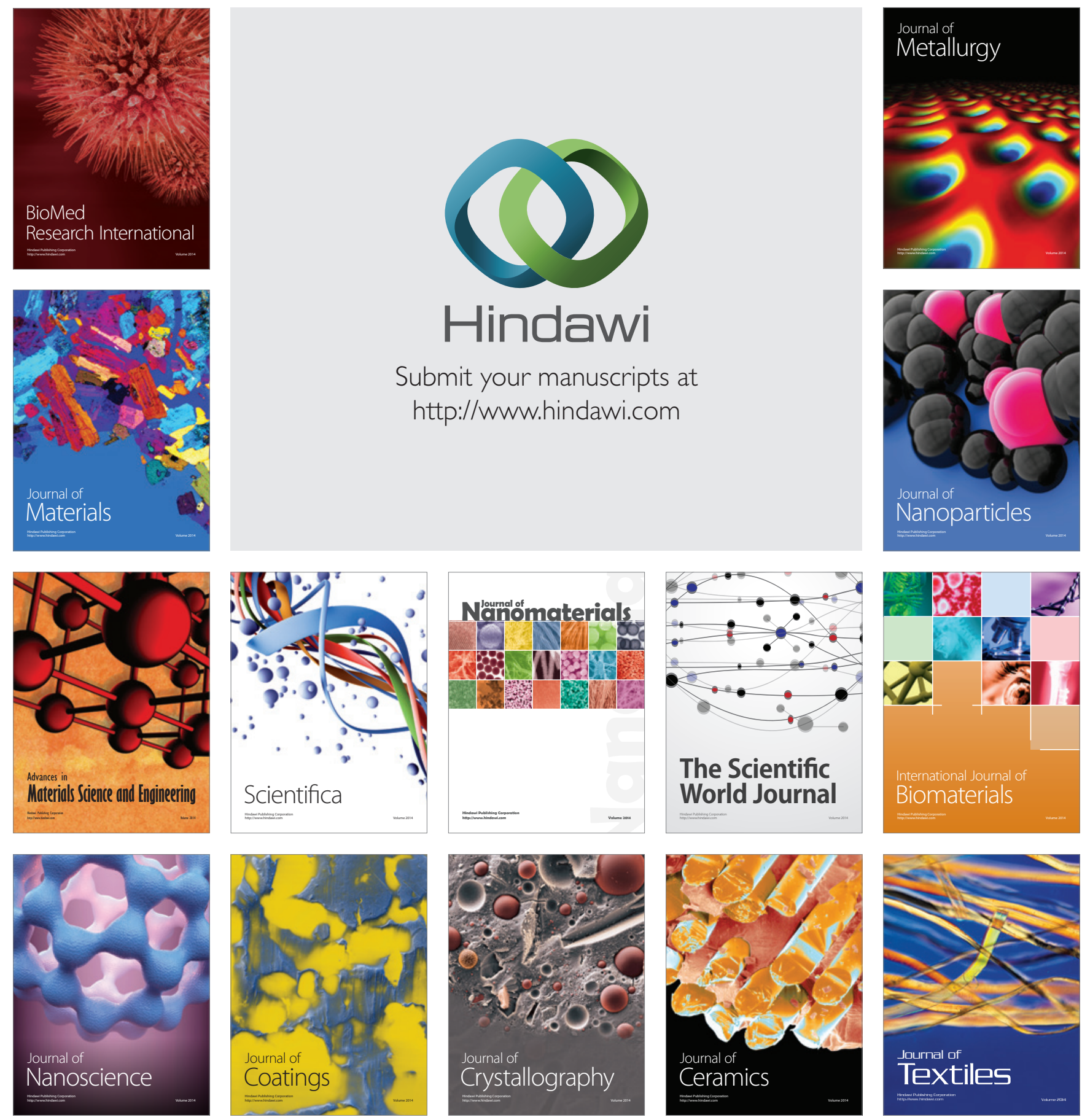